\title{
Thermal Decomposition of Illite
}

\author{
José Humberto de Araújo, Nagib Francisco da Silva, \\ Wilson Acchar, Uílame Umbelino Gomes* \\ Departament of Theoretical and Experimental Physics \\ Federal Univercity of Rio Grande do Norte - UFRN \\ P.O.Box 1641, 59072-970 Natal - RN, Brazil
}

Received: March 21, 2003; Revised: October 4, 2003

\begin{abstract}
The effect of heat treatment on illite in air at temperatures ranging from 750 to $1150{ }^{\circ} \mathrm{C}$ was studied using the Mössbauer effect in ${ }^{57} \mathrm{Fe}$. The dependence of the Mössbauer parameters and relative percentage of the radiation absorption area was measured as a function of the firing temperature. The onset of thermal structural decomposition occurred at $800^{\circ} \mathrm{C}$. With rising temperature, the formation of hematite $\left(\mathrm{Fe}_{2} \mathrm{O}_{3}\right)$ increased at the expense of the silicate mineral.
\end{abstract}

Keywords: Illite, Thermal decomposition, Mössbauer Spectroscopy

\section{Introduction}

Kaolinite and Illite are the clay minerals most commonly used for structural clay products in the traditional ceramic industry. Illite is probably the world's most widespread clay mineral, especially in the temperature latitudes and on the ocean floor ${ }^{1}$.

Illites are sheet silicates with low iron content. Their composition is quite variable and strongly dependent on their origin. Their structural family is $2: 1$ and they are normally dioctahedral. i.e., an octahedral sheet is sandwiched between two tetrahedral sheets of $\mathrm{SiO}_{2}$. The octahedral cations are surrounded by four oxygens and two hydroxyls in a trans- or cis- configuration. The octahedral sites are occupied by $\mathrm{Mg}^{+2}, \mathrm{Fe}^{+2}, \mathrm{Fe}^{+3}, \mathrm{Al}^{+3}$, etc. and are assigned by $\mathrm{M} 1$ if they are in the trans- position or by M2 if they are in the cisposition.

Although much work has been done on the thermal decomposition of sheet silicates in general, little has been published on illite in particular. Most of the studies on sheet silicates have been confined to biotites and micas. The thermal decomposition of muscovites and biotites has has been studied by infrared spectroscopy ${ }^{2}$. Mössbauer spectroscopy is extensively used by mineralogists, geologist and physicist to analyze clay minerals. The Mössbauer spectra of illites reported on in the literature have proved quite variable and strongly dependent on geological and

*e-mail: umbelino@dfte.ufrn.br

Articles presented at the XV CBECIMAT, Natal - RN, November de 2002. geochemical parameters ${ }^{4,5,6}$. The objective of this work is to study the thermal decomposition of illite as a function of the temperature, using Mössbauer spectroscopy.

\section{Experimental Procedure}

Illite samples from the ceramic industry of the state of Rio Grande do Norte (Brazil) were collected directly at the plant and heat treated at different temperatures in air. The raw material was milled for eight $\mathrm{h}$ in a planetary ball milling machine to a fine powder $(10 \mu \mathrm{m})$. After heat treatment, the samples were mounted in an acrylic sample holder and the Mössbauer spectra recorded at room temperature. The ${ }^{57} \mathrm{Fe}$ Mössbauer spectra were obtained in a transmission geometry, using a conventional constant acceleration spectrometer operating in triangular wave mode with a ${ }^{57} \mathrm{Co}$ source in a Rhodium matrix at room temperature. The spectrometer was calibrated with a $25 \mathrm{~mm}$ thick $\alpha$-Fe foil.

\section{Results}

Figures 1 shows the differential thermal analysis curves. The clay shows endothermic bands at 110 to $140{ }^{\circ} \mathrm{C}$ corresponding to water loss. The curve shows an endothermic reaction occurring between 470 and $580{ }^{\circ} \mathrm{C}$ caused by dehydroxilation of the octahedral sheet (constitutive wa- 
ter). The hydroxyl groups of the tetrahedral sheet are gradually removed up to $850{ }^{\circ} \mathrm{C}$. An exothermic peak resulting from crystal reformation (spinel phase) then appears between 850 and $920{ }^{\circ} \mathrm{C}$. It can also be inferred that the endothermic peaks at $1110-1150{ }^{\circ} \mathrm{C}$ are due to the formation of mullite and cristobalite phase. The existence of both endothermic and exothermic peaks is congruous with the results of reference ${ }^{7}$.

The Mössbauer spectrum of the untreated sample, which is shown in Fig. 2, was fitted using a least squares procedure with the sum of four Lorentz-shaped doublets corresponding to the quadrupolar splitting of $\mathrm{Fe}^{+2}$ and $\mathrm{Fe}^{+3}$ in the two M1 and M2 sites ${ }^{4}$. The two most intense central doublets are ascribed to $\mathrm{Fe}^{+3}$ in the $\mathrm{M} 1$ and $\mathrm{M} 2$ sites. The two right shifted doublets are attributed to $\mathrm{Fe}^{+2}$ in the same coordination sites (M1 and M2).

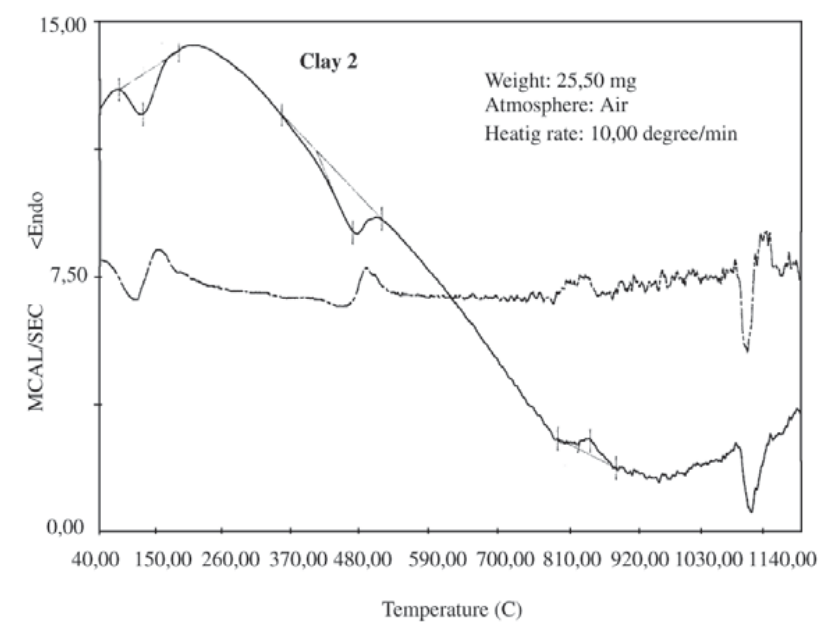

Figure 1. differential thermal analysis curves of the untreated sample.

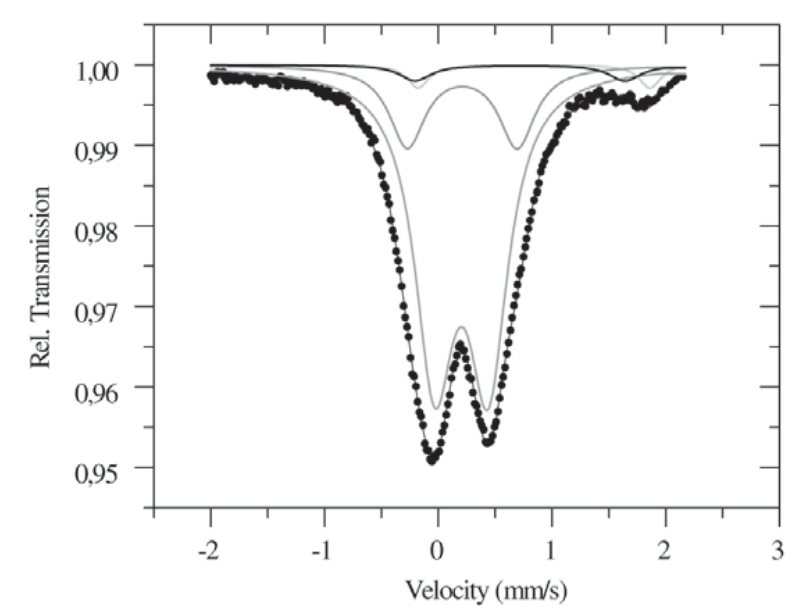

Figure 2. Mössbauer spectrum of untreated sample.
Table 1 shows the hyperfine Mössbauer parameters and the relative absorption area $(\mathrm{A}(\%))$ of $\mathrm{Fe}^{+2}$ and $\mathrm{Fe}^{+3}$ in each site position. The absorption area was directly proportional to the amount of iron in the sample.

Figure 3 shows the Mössbauer spectra for the samples heat treated at temperatures between 750 and $1150{ }^{\circ} \mathrm{C}$. The spectrum for the sample treated at $750{ }^{\circ} \mathrm{C}$ shows only two central doublets attributed to $\mathrm{Fe}^{+3}$, indicating that $\mathrm{Fe}^{+2}$ was completely oxidized. The high value of the quadrupolar splitting at this temperature may have been caused by dehydroxilation of $\mathrm{Fe}^{+3}$ hydroxide and a variety of iron sites due to $\mathrm{O}^{-2}$ and trapped water molecules bringing about distortion in the lattice ${ }^{3}$. The $\mathrm{Fe}^{3+}$ components were assigned to configurations (a) and (b) for higher and lower $\Delta$, respectively $^{3}$. The (a) configuration was ascribed to the less symmetric $\mathrm{Fe}^{3+}\left(\mathrm{O}_{5} \mathrm{OH}\right)$ coordination while the (b) configuration corresponded to the symmetric $\mathrm{Fe}^{3+}\left(\mathrm{O}_{6}\right)$ coordination. The samples heat treated at temperatures of 800 to $1150{ }^{\circ} \mathrm{C}$ also displayed Mössbauer spectra with the same two central doublets found in the sample treated at $750{ }^{\circ} \mathrm{C}$. In addition, a sextet observed in all spectra was found to corre-

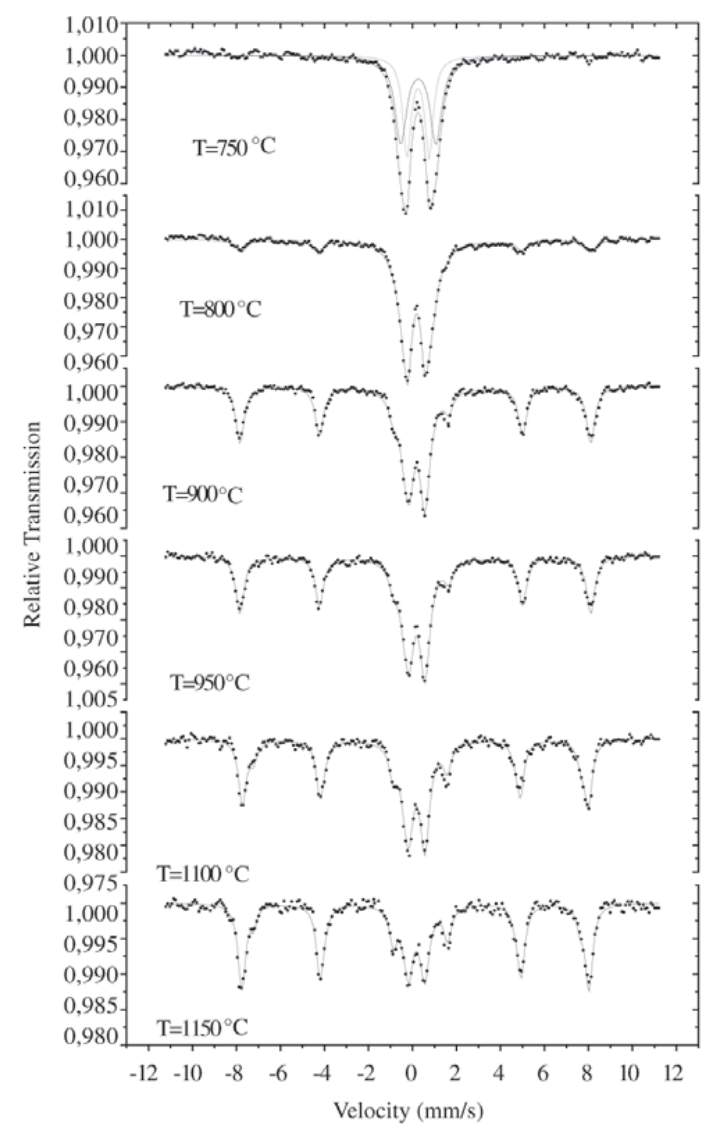

Figure 3. Mössbauer spectra of heat treated samples. 
Table 1. Mössbauer parameters for untreated sample.

\begin{tabular}{lcccc}
\hline F.T $\left({ }^{\circ} \mathrm{C}\right)$ & $\mathrm{H}(\mathrm{KOe})$ & $\Delta(\mathrm{mm} / \mathrm{s})$ & $\delta(\mathrm{mm} / \mathrm{s})$ & $\mathrm{A}(\%)$ \\
\hline 750 & - & 1.60 & 0.26 & 55.3 \\
& - & 1.05 & 0.25 & 44.7 \\
& - & 1.21 & 0.21 & 52.1 \\
800 & - & 0.75 & 0.18 & 32.8 \\
& 494 & -0.10 & 0.25 & 15.1 \\
& - & 1.15 & 0.16 & 34.3 \\
850 & - & 0.72 & 0.19 & 30.3 \\
& 494 & -0.12 & 0.26 & 35.4 \\
& - & 0.90 & 0.14 & 33.0 \\
900 & - & 0.68 & 0.21 & 22.1 \\
& 495 & -0.12 & 0.26 & 44.9 \\
& - & 0.90 & 0.14 & 32.8 \\
950 & - & 0.72 & 0.21 & 21.9 \\
& 495 & -0.12 & 0.26 & 45.3 \\
& - & 0.88 & 0.14 & 22.8 \\
1100 & - & 0.69 & 0.20 & 21.9 \\
& 462 & -0.06 & 0.27 & 14.3 \\
& 489 & -0.11 & 0.24 & 41.7 \\
& - & 0.86 & 0.16 & 13.1 \\
1150 & - & 0.70 & 0.19 & 18.1 \\
& 460 & -0.07 & 0.27 & 9.5 \\
& 490 & -0.12 & 0.25 & 59.3 \\
\hline \multirow{3}{*}{850}
\end{tabular}

Table 2. Mössbauer parameters for Illite as a function of the firing temperature.

\begin{tabular}{llccl}
\hline & & $\delta(\mathrm{mm} / \mathrm{s})$ & $\Delta(\mathrm{mm} / \mathrm{s})$ & $\mathrm{A}(\%)$ \\
\hline $\mathrm{Fe}^{+3}$ & M1 & 0.21 & 0.96 & 18.6 \\
& M2 & 0.20 & 0.47 & 74.9 \\
$\mathrm{Fe}^{+2}$ & & 0.84 & 2.02 & 3.2 \\
& & 0.72 & 1.84 & 3.3 \\
\hline
\end{tabular}

spond to magnetic hyperfine splitting. A marked change was also observed in the samples' color, which started with orange at $800{ }^{\circ} \mathrm{C}$ and intensified to a bright red at $1150{ }^{\circ} \mathrm{C}$. The sextet, with a hyperfine field of $495 \mathrm{kOe}$, was very well fitted with the hematite Mössbauer parameters. X-ray diffraction results published in the literature confirm the presence of Hematite at $1150{ }^{\circ} \mathrm{C}^{9}$. The low hyperfine fields $462 \mathrm{kOe}$ and $489 \mathrm{kOe}$ observed in samples fired at $1100^{\circ} \mathrm{C}$ may be attributed to the small particle size. Similar values have been reported in the literature ${ }^{8}$.

As can be seen from the above spectra, the absorption area of the hematite subspectra increased as the temperature rose to the detriment of the silicate subspectra absorption area, suggesting that the hematite thus formed was a product of the thermal decomposition of the silicate. Table 2 shows the Mössbauer parameters and relative absorption areas of the silicate and hematite subspectra.

The above results for illite are very different from those of the thermal decomposition of other sheet silicates reported in the literature. For example, a Mössbauer study of heat treatment in air of biotite showed no evidence of hematite formation below $900{ }^{\circ} \mathrm{C}^{3}$, while another study reported hematite formation only at $980{ }^{\circ} \mathrm{C}^{8}$.

\section{Conclusions}

We investigated the effect of heat treatment in air on illite. The results of this study led us to the following conclusions:

1. The changes in Mössbauer spectra were correlated with oxidation and dehydroxilation.

2. Onset of the dehydroxilation process began prior to the decomposition of the original silicate structure.

3. The magnetic pattern that appeared up to $800^{\circ} \mathrm{C}$ was attributed to hematite.

\section{References}

1. Browenll, W.E. Structural Clay Products. Springer-Verlag 1976.

2. Addison C.C.; Addison, W.E.; Neal, G.H.; Sharp, J.H. J. Chem. Soc. p. 1468, 1962.

3. Högg, C.S.; Meads, R.E. Min. Mag. v. 40, p. 79,1975.

4. Raclavsky, K.; Sitck, J.; Lipka, J. Proc. 5th Int. Conf. Mössbauer Spectroscopy, 368, Bratislava 1973.

5. Malathi, N.; Puri, S.P.; Sarawat, I.P. J. Phys. Soc. Japan v. 26, p. 680, 1969.

6. Coey, J.M.D. Atomic Energy Review v. 18, p. 73, 1980.

7. Smykatz-kloss, W., "Differential Thermal Analysis: Aplication and Results in Mineralogy", Springer Verlag, New York, v. 974, 1973.

8. Chandra, U.; Lokanathan, S. J. Phys. D: Appl. Phys. v. 15, p. 2331, 1982.

9. Silva, N.F. Tese de Mestrado, UFRN, 1995. 
